\title{
PENGARUH SUHU DAN LAMA WAKTU PENYANGRAIAN TERHADAP MASSA JENIS BIJI KOPI ROBUSTA MENGGUNAKAN MESIN ROASTING TIPE HOT AIR
}

\author{
${ }^{1)}$ A Mafaza Kanzul Fikri, ${ }^{1)}$ Trapsilo Prihandono, ${ }^{1)}$ Lailatul Nuraini \\ ${ }^{1)}$ Program Studi Pendidikan Fisika, FKIP, Universitas Jember \\ E-mail: aankfkip@gmail.com
}

\begin{abstract}
An important stage that will determine the quality of ready-to-consume coffee is roasting. This method has been developed and used to obtain the best and specific quality of coffee brewing. The type of coffee greatly has influenced the quality characteristics of the brewed coffee produced. Coffee beans will not have a high commercial value before being subjected to a roasting process for the formation of the best aroma and taste. Roasting is a combination of time and temperature that changes the structure and chemical properties in coffee beans through the pyrolysis process. Even high-quality coffee beans cannot have maximum aroma and flavor if the roasting process is not done properly. This research used a roasting machine type Hot Air Roasting. The results of this research was the decrease in density was related with the longer of roasting process. The weight of coffee will decrease because the water content in coffee beans has begun to decrease. This research showed that the longer of coffee beans are roasted, the better the results of heating. The final results obtained that temperature continues to rise but the density decreases. This showed there was inverse relationship between temperature and density of coffee and the best roasting results and can be used for brewing robusta coffee at $200^{\circ} \mathrm{C}$ in 15-20 minutes.
\end{abstract}

Key word: Hot Air Roasting, Robusta Coffee, Temperature

\section{PENDAHULUAN}

Buah kopi pada umumnya memiliki anatomi yang sama yaitu kulit ceri, lapisan lendir, lapisan perkamen, lapisan perak (silverskin), biji hijau (green beans), Struktur anatomi tersebut berfungsi untuk melindungi kualitas biji kopi (green beans). Komposisi kimia dari biji kopi hijau berbeda-beda tergantung kepada tanah tempat tumbuh, jenis kopi, derajat kematangan, cara pengolahan, dan kondisi penyimpanan (Clarke dan Macrae, 1985). Ada dua senyawa utama yang membuat kopi memiliki citarasa dan aroma yang disukai masyarakat.Dua senyawa tersebut adalah kafein yang berpengaruh terhadap rangsangan metabolisme tubuh, dan kafeol yang menghasilkan aroma yang khas dari kopi (Almada, 2009). Kopi yang dipetik pada saat tua, merupakan kopi dengan mutu tinggi. Sebaliknya kopi yang berwarna kuning dan hijau namum sudah dipetik akan mengakibatkan aroma dan rasa yang kurang. Pencampuran antara kopi tua dan muda akan menyebabkan menurunnya kualitas kopi yang dihasilkan.

Penelitian menggunakan mesin roasting tipe Hot Air Roasting atau dengan nama lainnya Air Roasting 
adalah metode sangrai kopi yang berbeda. Proses sangrai kopi bukan pada permukaan roaster tapi di udara, metode roasting kopi ini dikenalkan oleh Michael Sivetz seorang insinyur kimia dan konsultan industri kopi dunia. Kebanyakan masyarakat pribumi mengenal drum roasters (sangrai dengan drum), prosesnya dengan menyimpan udara panas ke alat sangrai kopi, kemudian biji jatuh dan menyentuh permukaan yang panas untuk kemudian mencapai level roasting terbaik untuk biji kopi. Metode drum roaster memiliki banyak kekurangan kalau dibandingkan dengan Air Roasting Kopi. Air roasting kopi memberikan hasil sangrai kopi yang tidak bisa penikmat kopi dapatkan di drum roasting (Rothfos, 1986).

Berdasarkan penelitian yang dilakukan oleh Purnamayanti et al., (2017) menyatakan perlakuan suhu dan lama penyangraian berpengaruh nyata terhadap rendemen biji kopi arabika sangrai dan keasaman seduhan kopi. Penelitian berikutnya oleh Edvan et al., (2016) menunjukan bahwa ada pengaruh suhu dan lama penyangraian pada biji kopi robusta terhadap kadar air biji kopi sebelum dilakukan penyangraian adalah $12 \%$. Penyangraian pada suhu $200^{\circ} \mathrm{C}$ selama 10 menit menghasilkan biji kopi yang tersangrai dengan baik. Tekstur biji kopi selama penyangraian cenderung lebih rapuh dilihat dari nilai tegangan patah. Keterkaitan pengaruh suhu dan lama waktu penyangraian terhadap perubahan masa jenis biji kopi robusta sangat berpengaruh terhadap perubahan fisik yang terjadi pada biji kopi setelah dilakukannya proses penyangraian dan itu sangat membantu menentukan kualitas biji kopi yang siap seduh dan masyarakat bisa mengetahui kualitas biji kopi yang baik hanya dengan cara menghitung massa jenisnya.

\section{METODE PENELITIAN}

Jenis penelitian ini menggunakan penelitian Eksperimen. Penelitian Eksperimen merupakan penelitian yang digunakan untuk mencari pengaruh perlakuan tertentu terhadap yang lain dalam kondisi yang terkendalikan (Sugiyono, 2011). Untuk dapat melaksanakan suatu eksperimen yang baik, perlu dipahami terlebih dahulu segala sesuatu yang berkait dengan komponen-komponen eksperimen, Baik yang berkaitan dengan jenis-jenis variabel, hakekat eksperimen, karakteristik, tujuan, syarat-syarat eksperimen, langkah-langkah penelitian eksperimen, dan bentukbentuk desain penelitian eksperimen. Selanjutnya, Dalam penelitian eksperimen dikenal beberapa variabel.

Analisis datanya dapat dijelaskan setelah mendapatkan hasil data penelitian tersebut. Cara mendapatkan hasil data sebelum meroasting biji kopi robusta, terlebih dahulu mengukur massa dan volume biji kopi, setalah itu menghitung massa jenis biji kopi sebelum dilakukannya roasting. Setelah mendapatkan massa jenis biji kopi maka melakukan roasting biji kopi dengan varian suhu dan lama waktu yang sudah ditentukan, kemudian mencatat hasil roasting sesuai suhu dan lama waktu penyangraian sehingga dapat mengukur volume dan massa biji kopi setelah roasting. Setiap tahap pelaksanaan penelitian ini dilakukan masing-masing 3 kali perlakuan. Tahap selanjutnya menghitung massa biji kopi. Setelah didapatkan massa jenis biji kopi yang sudah di roasting, maka dapat diketahui pengaruh suhu dan lama waktu penyangraian terhadap 
massa jenis biji kopi dan dapat dibandingkan perubahan massa jenis biji kopi robusta sebelum dan sesudah di roasting

\section{HASIL DAN PEMBAHASAN}

Penelitian dilaksanakan di Garage of Hore. Garage of Hore merupakan tempat meroasting kopi, sekolah barista kopi dan tempatnya para pecinta kopi berbagi ilmu di daerah jember tepatnya di jalan Semeru. Sebelum penelitian berlangsung, peralatan yang disiapkan yaitu: alat roasting tipe hot air, timbangan digital, gelas ukur dan biji kopi robusta yang diambil langsung dari kebun kopi desa Kebonrejo kecamatan Kalibaru kabupaten Banyuwangi. Berdasarkan hasil penelitian didapatkan hasil sebagaimana ditunjukkan pada Gambar 1 berikut.

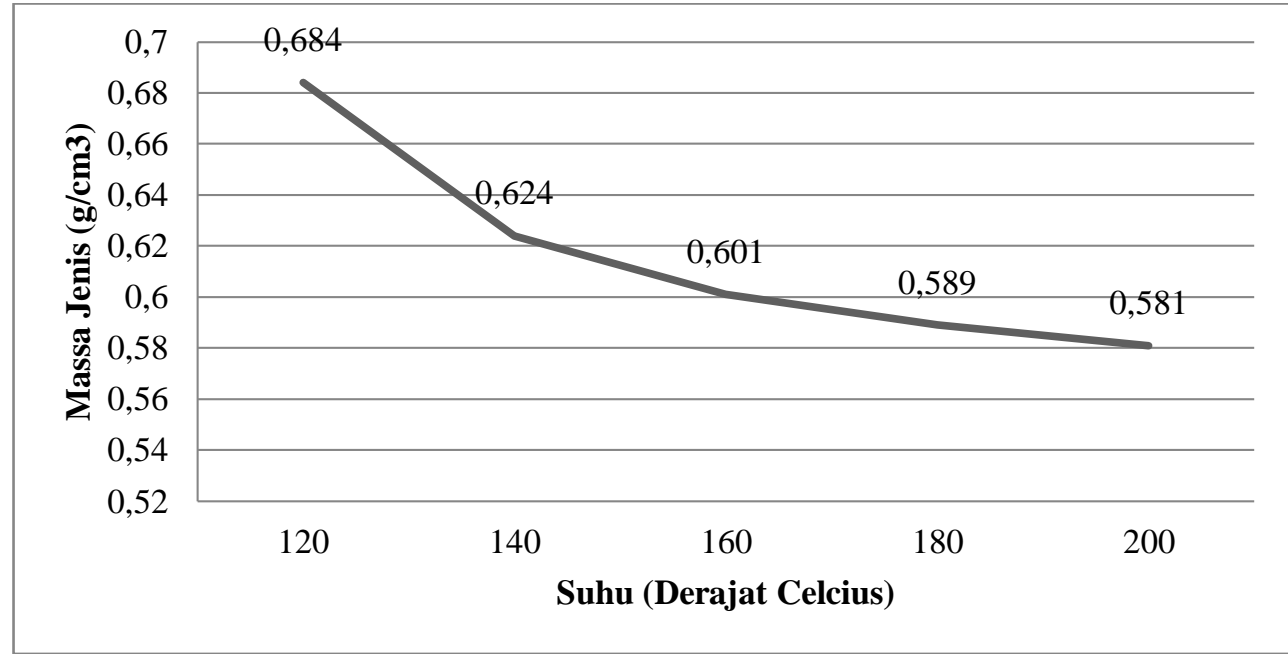

Gambar 1. Grafik hasil penelitian dengan Penyangraian Selama 5 Menit

Berdasarkan Grafik 1 dapat $\mathrm{g} / \mathrm{cm}^{3}$, setelah di sangrai selama 5 diketahui bahwa massa jenis kopi menit pada suhu $120-200^{\circ} \mathrm{C}$ ternyata setelah disangrai selama 5 menit dan massa jenis kopi semakin berkurang suhunya dinaikkan maka menghasilkan yaitu sebesar $0,066 \mathrm{~g} / \mathrm{cm}^{3}, 0,126 \mathrm{~g} / \mathrm{cm}^{3}$, massa jenis yang semakin berkurang $0,149 \mathrm{~g} / \mathrm{cm}^{3}, 0,161 \mathrm{~g} / \mathrm{cm}^{3}$, dan 0,169 atau lebih kecil dari massa jenis mula- $\mathrm{g} / \mathrm{cm}^{3}$. Rata-rata pengurangan massa mula. Diketahui massa jenis mula-mula jenis kopi selama 5 menit yaitu sebesar kopi sebelum disangrai adalah $0,75 \quad 0,134 \mathrm{~g} / \mathrm{cm}^{3}$. 


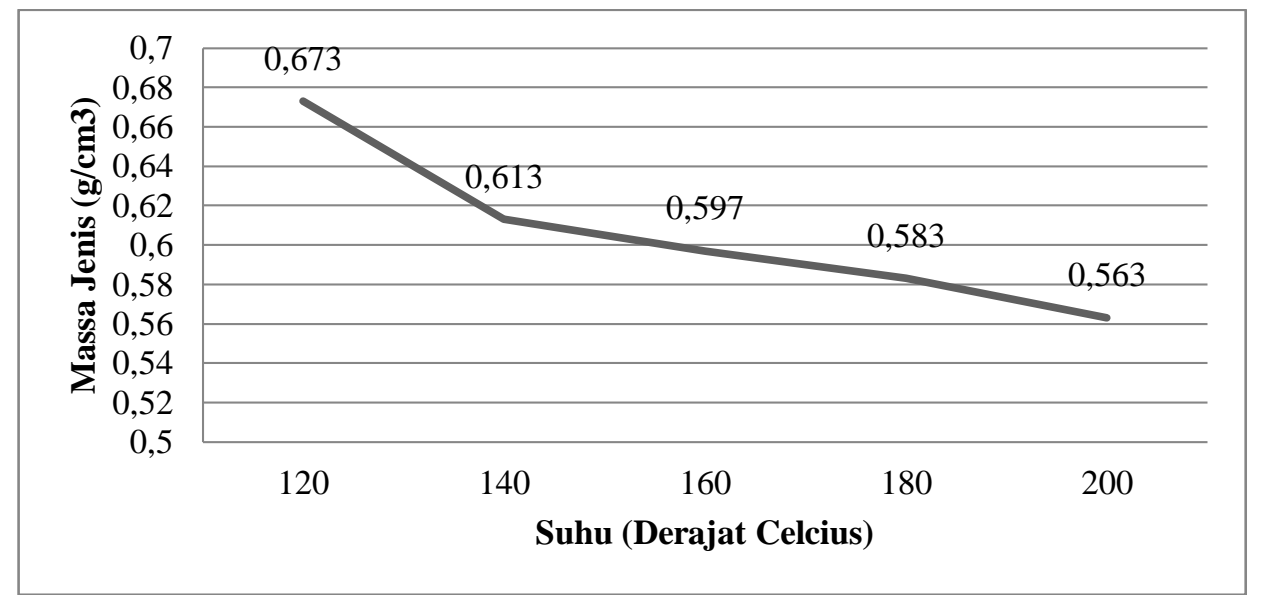

Gambar 2 Hasil penelitian dengan Penyangraian Selama 10 Menit

Berdasarkan Gambar 2 dapat dijelaskan bahwa massa jenis kopi setelah disangrai dalam 10 menit dan suhunya dinaikkan maka menghasilkan massa jenis yang semakin berkurang atau lebih kecil dari massa jenis mulamula. Pada suhu $120-200^{\circ} \mathrm{C}$ terjadi pengurangan massa jenis secara berurutan yaitu sebesar $0,077 \mathrm{~g} / \mathrm{cm}^{3}$, $0,137 \mathrm{~g} / \mathrm{cm}^{3}, 0,153 \mathrm{~g} / \mathrm{cm}^{3}, 0,167 \mathrm{~g} / \mathrm{cm}^{3}$, dan $\quad 0,187 \quad \mathrm{~g} / \mathrm{cm}^{3}$. Rata-rata pengurangan massa jenis kopi selama 10 menit yaitu sebesar $0,144 \mathrm{~g} / \mathrm{cm}^{3}$.

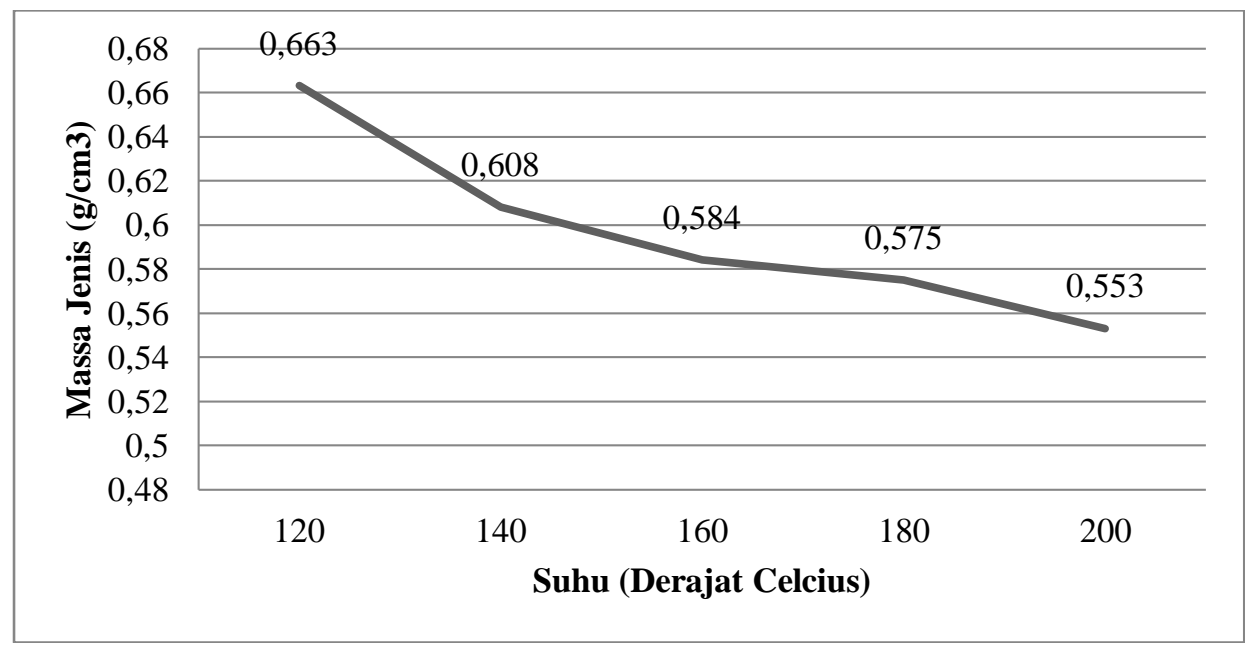

Gambar 3 Hasil penelitian dengan Penyangraian Selama 15 Menit

Berdasarkan Gambar 3 dapat pengurangan massa jenis secara dijelaskan bahwa massa jenis kopi berurutan yaitu sebesar $0,087 \mathrm{~g} / \mathrm{cm}^{3}$, setelah disangrai dalam 15 menit dan $0,142 \mathrm{~g} / \mathrm{cm}^{3}, 0,166 \mathrm{~g} / \mathrm{cm}^{3}, 0,175 \mathrm{~g} / \mathrm{cm}^{3}$, suhunya dinaikkan maka menghasilkan dan $0,197 \quad \mathrm{~g} / \mathrm{cm}^{3}$. Rata-rata massa jenis yang semakin berkurang pengurangan massa jenis kopi selama atau lebih kecil dari massa jenis mula- 15 menit yaitu sebesar $0,153 \mathrm{~g} / \mathrm{cm}^{3}$. mula. Pada suhu $120-200^{\circ} \mathrm{C}$ terjadi 



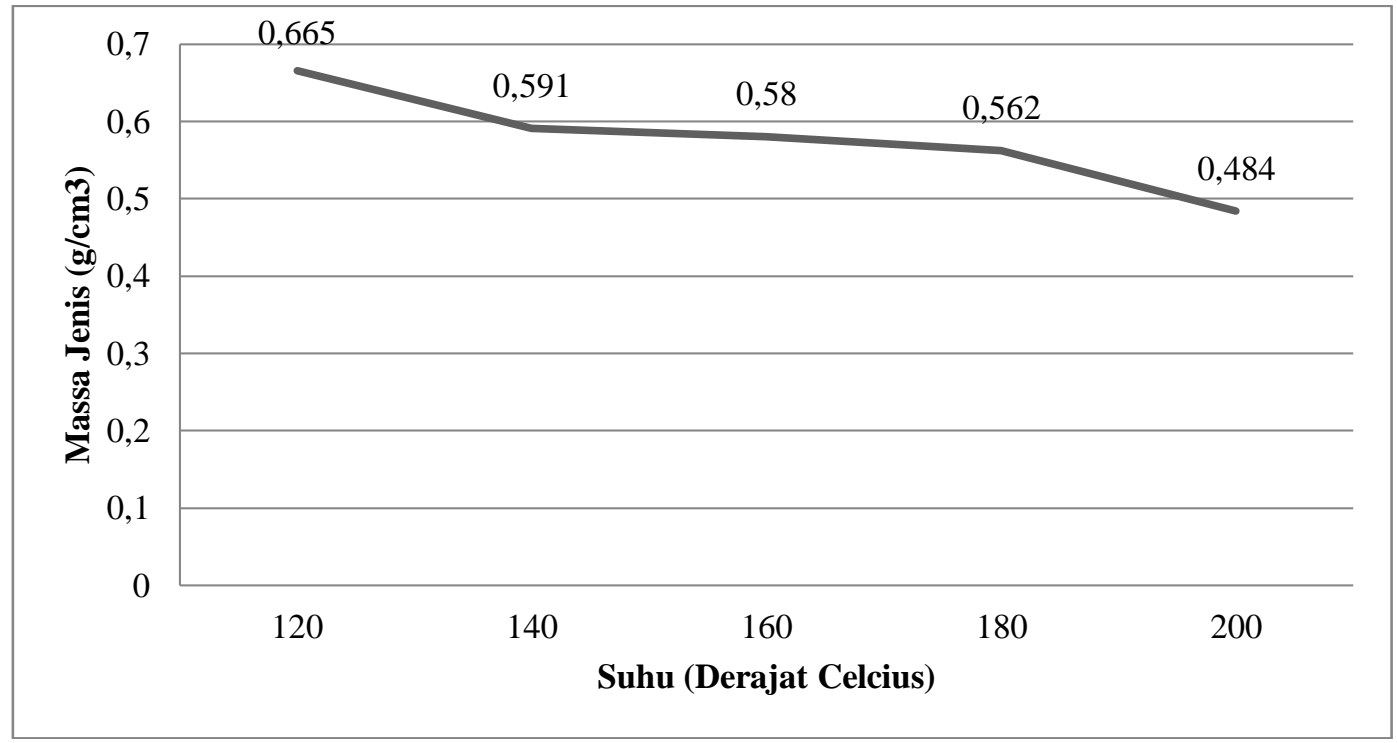

Gambar 4. Penelitian dengan Penyangraian Selama 20 Menit

Berdasarkan Gambar 4 dapat pengurangan massa jenis secara dijelaskan bahwa massa jenis kopi berurutan yaitu sebesar $0,085 \mathrm{~g} / \mathrm{cm}^{3}$, setelah disangrai dalam 20 menit dan $0,159 \mathrm{~g} / \mathrm{cm}^{3}, 0,170 \mathrm{~g} / \mathrm{cm}^{3}, 0,188 \mathrm{~g} / \mathrm{cm}^{3}$, suhunya dinaikkan maka menghasilkan dan $0,266 \mathrm{~g} / \mathrm{cm}^{3}$. Rata-rata massa jenis yang semakin berkurang pengurangan massa jenis kopi selama atau lebih kecil dari massa jenis mula- 20 menit yaitu sebesar $0,174 \mathrm{~g} / \mathrm{cm}^{3}$. mula. Pada suhu $120-200^{\circ} \mathrm{C}$ terjadi

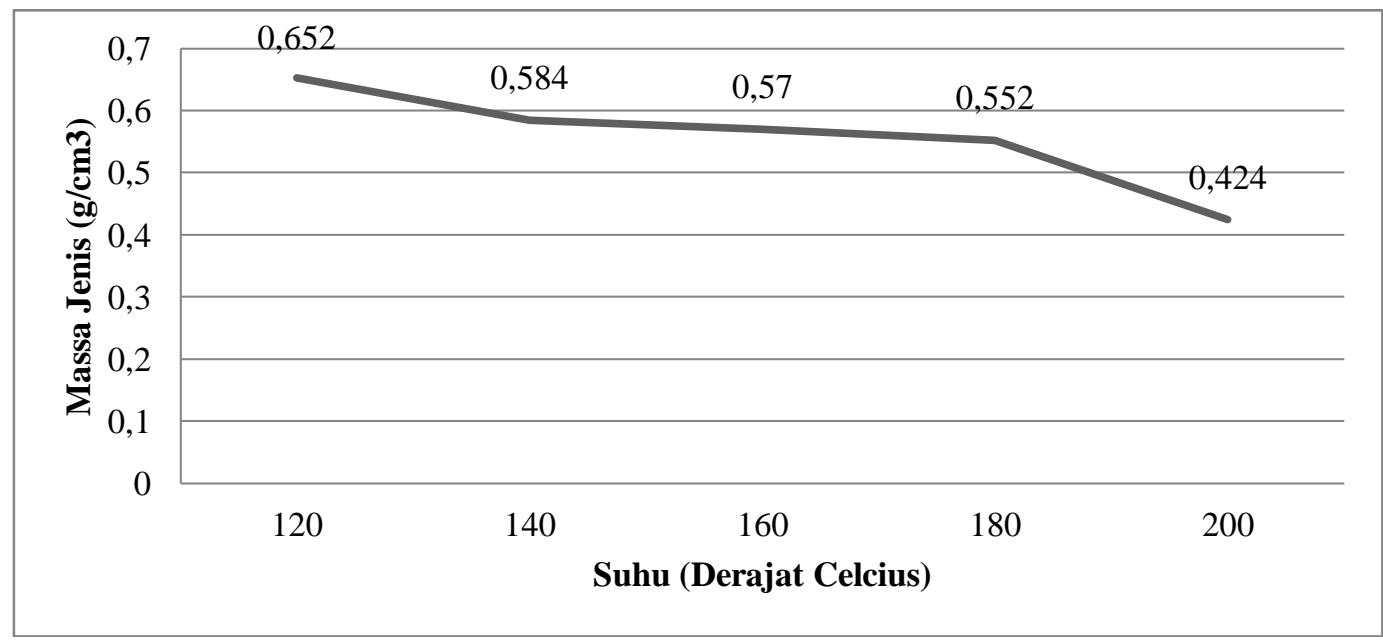

Gambar 5 Penelitian dengan Penyangraian Selama 25 Menit

Berdasarkan Gambar 5 dapat dijelaskan bahwa massa jenis kopi setelah disangrai dalam 25 menit dan suhunya dinaikkan maka menghasilkan massa jenis yang semakin berkurang atau lebih kecil dari massa jenis mulamula. Pada suhu $120-200^{\circ} \mathrm{C}$ terjadi pengurangan massa jenis secara berurutan yaitu sebesar $0,098 \mathrm{~g} / \mathrm{cm}^{3}$, $0,166 \mathrm{~g} / \mathrm{cm}^{3}, 0,180 \mathrm{~g} / \mathrm{cm}^{3}, 0,198 \mathrm{~g} / \mathrm{cm}^{3}$, 
dan $\quad 0,326 \mathrm{~g} / \mathrm{cm}^{3} . \quad$ Rata-rata pengurangan massa jenis kopi selama 25 menit yaitu sebesar $0,194 \mathrm{~g} / \mathrm{cm}^{3}$.

Hasil penurunan massa jenis yang dibahas paragrap sebelumnya menunjukkan semakin lama diroasting maka berat kopi akan mengalami penurunan dikarenakan kadar air dalam biji kopi sudah mulai mengalami penurunan. Hal ini menunjukkan semakin lama biji kopi itu diroasting maka semakin baik hasil dari pemanasan. Proses penelitian ini menggunakan mesin roasting tipe hot air. Hot air merupakan salah satu type mesin roasting yang bagus dan efisien, karena pemanasan yang dilakukan oleh mesin tersebut menggunakan energi listrik. Hasil akhir yang didapatkan dalam penelitian ini suhu yang terus naik tetapi massa jenis semakin berkurang. Hal ini menunjukkan hubungan terbalik antara suhu dengan massa jenis kopi dan hasil roating terbaik dan bisa digunakan untuk penyeduhan kopi robusta adalah dalam suhu $200^{\circ} \mathrm{C}$ dalam waktu $15-20$ menit.

Hal ini sejalan dengan hasil penelitian yang dilakukan oleh Purnamayanti et al., (2017) menyatakan perlakuan suhu dan lama roasting berpengaruh nyata terhadap rendemen biji kopi arabika sangrai dan keasaman seduhan kopi. Penelitian berikutnya oleh Edvan et al., (2016) menunjukan bahwa ada pengaruh suhu dan lama roasting pada biji kopi robusta terhadap kadar air biji kopi sebelum dilakukan roasting adalah 12 $\%$. Penelitian berikutnya oleh Agustina et al., (2019) disimpulkan bahwa berdasarkan analisis sidik ragam diketahui variasi suhu dan lama roasting berpengaruh sangat nyata terhadap kadar air dan kadar kafein kopi Arabika. Semakin tinggi suhu dan sejmakin lama waktu roasting maka semakin gelap warna kopi Arabika hasil roasting. Berdasarkan uji organoleptik, kopi Arabika yang paling disukai panelis adalah kopi yang disangrai pada suhu $210^{\circ} \mathrm{C}$ dengan lama roasting 10 menit.

Penelitian berikutnya oleh Nugroho et al., (2009) menunjukkan bahwa roasting kopi dengan berbagai variasi suhu akan menyebabkan terjadinya perubahan sifat fisik pada biji kopi tersebut, yaitu penurunan kada air yang lebih cepat, peningkatan kerapuhan dan mempercepat roasting dengan suhu rendah $\left(160^{\circ} \mathrm{C}\right)$ menghasilkan biji kopi yang belum tersangrai selama 12 menit dilihat dari perubahan warna dan bau yang ditimbulkan. Roasting pada suhu $200^{\circ} \mathrm{C}$ selama 10 menit menghasilkan biji kopi yang tersangrai dengan baik. Tekstur biji kopi selama roasting cenderung lebih rapuh dilihat dari nilai tegangan patah. Keterkaitan pengaruh suhu dan lama waktu roasting terhadap perubahan masa jenis biji kopi robusta sangat berpengaruh terhadap perubahan fisik yang terjadi pada biji kopi setelah dilakukannya proses roasting dan itu sangat membantu menentukan kualitas biji kopi yang siap seduh dan masyarakat bisa mengetahui kualitas biji kopi yang baik hanya dengan cara menghitung massa jenisnya.

\section{SIMPULAN DAN SARAN}

Suhu roasting terus mengalami kenaikan tetapi massa jenis semakin berkurang, hal ini menunjukkan hubungan terbalik antara suhu dengan massa jenis biji kopi robusta. Semakin lama diroasting maka berat kopi akan mengalami penurunan dikarenakan kadar air dalam biji kopi sudah mulai mengalami penurunan, hal ini menunjukkan hubungan terbalik antara lama waktu dengan massa jenis biji kopi robusta. Hasil suhu roasting terbaik dan bisa digunakan untuk 
penyeduhan adalah dalam suhu $200^{\circ} \mathrm{C}$ dalam waktu 15-20 menit.

Kesalahan yang terjadi pada penelitian ini ialah dalam beberapa penelitian awal adanya biji kopi yang jatuh waktu meletakkan biji kopi yang setelah diroasting pada gelas ukur, antisipasinya pada penelitian berikutnya biji kopi yang setelah diroasting lebih hati-hati meletakkannya pada gelas ukur agar tidak terjadi lagi kesalahan seperti diawal penelitian.

\section{DAFTAR PUSTAKA}

Agustina R., D. Nurba, W. Antono, dan R. Septiana. 2019. Pengaruh Suhu Dan Lama Penyangraian Terhadap Sifat Fisik-Kimia Kopi Arabika dan Kopi Robusta. Prosiding Seminar Nasional, ISBN: 978-602-52982-1-9.

Almada, Deva P. 2009. Pengaruh Perubah Proses Dekafeinasi Kopi dalam Reaktor KolomTunggal Terhadap Mutu Kopi. Tesis. Bogor: Fakultas Teknologi Pertanian Institut Pertanian Bogor.

Clarke, R. J. And R. Macrae. 1985. Commercial and TechnicoLegal Aspects. London and New York. Elsevier Applied Science. Vol 6. ISBN: 1851662375.

Edvan, B. T., Rachmad E., dan Made S. 2016. Pengaruh Jenis dan Lama Penyangraian pada Mutu Kopi Robusta (Coffea robusta). Jurnal AIP. 4(1): 31-40.

Fuferti, Z. M. A., Syakbaniah dan Ratnawulan. 2013.
Perbandingan Karakteristik Fisis Kopi Luwak (Civet coffee) dan Kopi Biasa Jenis Arabika. Pillar Of Physics. 2(3).

Nugroho, J., J. Lumbanbatu, dan S. Rahayoe. 2009. Pengaruh Suhu Dan Lama Penyangraian Terhadap Sifat Fisik-Mekanis Biji Kopi Robusta.Makalah Bidang Teknik Produk Pertanian ISSN 2081-7152.

Purnamayanti, N. P. A., I.B. P. Gunadnya, dan G. Arda. 2017. Pengaruh Suhu dan Lama Penyangraian terhadap Karakteristik Fisik dan Mutu Sensori Kopi Arabika (Coffea arabica L). Jurnal Beta (Biosistem Dan Teknik Pertanian). 5(2).

Sivetz, M. 1979. Coffee Technology. The AVI Publishing Company, Inc., Westport, Connecticut.

Sugiyono. 2011. Metode Penelitian Kuantitatif Kualitatif dan $R \& D$. Bandung: Alfabeta. 